\title{
Similarities and Differences Between Pigments in Pre-Hispanic Murals and Codices: A Study by Analytical Electron Microscopy
}

\author{
J. Arenas Alatorre ${ }^{1}$, C. González Tirado ${ }^{2}$, Y. Silva-Velásquez ${ }^{3}$ and J. L. Ruvalcaba Sil ${ }^{1}$
}

1 Institute of Physics, UNAM, Circuito de la Investigación Científica S/N, Ciudad Universitaria, Delegación Coyoacán, Mexico DF . C.P. 04510, Mexico

2 Instituto Nacional de Antropología e Historía, INAH. Mexico

3 University of Oxford, Dyson Perrins Buildings South Parks Road, Oxford OX1 3QY, UK

Optical microscopy (OM) and Scanning Electron Microscopy (SEM) have been widely used in the analysis of pigments, metals and ceramics, among others [1-3]. However, TEM analysis is used less frequently, probably due to the small amount of material used for the analysis, which may be not considered representative of the object. Nevertheless, one of the major contributions of TEM is in the study of ancient pigments, providing information of the raw material, details of the technology used in their production, as well as information on possible cultural exchanges among different groups [4]. In this work we present the study by Analytical Electron Microscopy (Scanning and Transmission) of blue, yellow, white, red, green and black pigment samples of the prehispanic murals from the Mayapan site, located in Yucatan, Mexico and the "Colombino Codex" (Figure 1). Mayapan is considered the last great Maya capital, and therefore, the most important city of from the post-classical period of this civilization (1050- 1441 A.D.). On the other hand, the importance of the codices is that they represent social life forms and the knowledge generated in different periods of history from pre-Hispanic times to the early colonial period (XVI-XVII centuries). Of these, knowledge of the materials used in its production is very limited. In particular the "Colombino Codex" is of pre-Hispanic origin and is interpreted as the biography of the warrior-8 Deer Jaguar Claw (1063-1115 A.D.), one of the most important governors of the Mixteca history.

For the Mayapan site, Electron Microscopic analyses indicate that the blue pigment consists of palygorskite fibers, $\mathrm{Mg}_{5}(\mathrm{Si}, \mathrm{Al})_{8} \mathrm{O}_{20}(\mathrm{OH})_{2} \mathrm{H}_{2} \mathrm{O}$, similar to those identified in the Maya blue [5] (Figure $2 \mathrm{a})$. On the other hand goethite $(\mathrm{FeO} . \mathrm{OH})$ was identified in the olive colored pigment, whilst the white color is composed of calcite $\left(\mathrm{CaCO}_{3}\right)$. Iron was identified in large proportion in the black pigment (Figure 3a) and hematite $\left(\mathrm{Fe}_{2} \mathrm{O}_{3}\right)$ was found in the red pigment Figure 4a. Moreover, the "Colombino Codex" constituts of 8 pieces of deer or berrendo leather support joined with agave thread on which there is a film of gypsum $\left(\mathrm{Ca}\left(\mathrm{SO}_{4}\right)\left(\mathrm{H}_{2} \mathrm{O}\right)_{2}\right)$ used as support on which material of other colors are deposited. Palygorskite clay was also identified in the blue pigment (Figure 2b) and carbonaceous structures were found in the black coloring (Figure 3b). In the case of red pigment Fe not was not detected, so that it may have an organic origin, possibly "cochineal" (Figure 3b). Some of the crystalline phases present in the different colors were identified By HRTEM.

References:

[1] G. Martinez, et.al. , Appl. Radiat. Isot. 63 (2005)705.

[2] B. Wagner, et.al. Microchim. Acta 162(2008)415.

[3]. J. Arenas-Alatorre, et.al, Appl. Phys. A 98(2010)617.

[4] J. Perez-Arantegui, et.al. J. Am. Ceram. Soc. 84(2001)2.

[5] M.J. Yacaman, et.al.. Science 273 (1996) 223-225

[6] The authors acknowledge the technical assistance of R. Hernández, J. Cañetas, M. Monroy , D. Quiterio and J. A. Lara. 


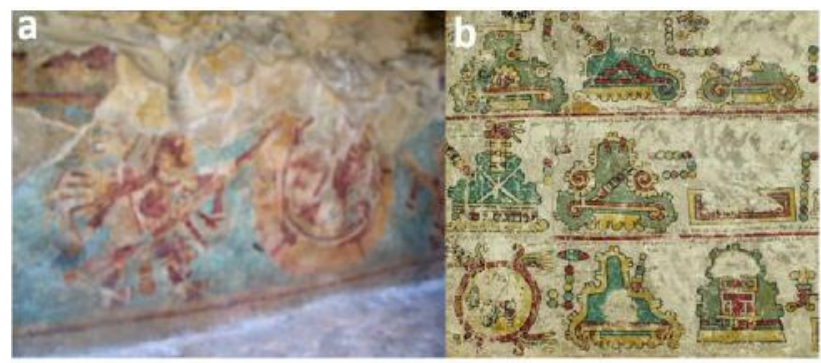

Figure 1. a) Mural Painting from Mayapan, the last great Maya capital in the post-classical period (1050-1441 A.D.). b) "Colombino Codex", from pre-Hispanic origin has been interpreted as biography Warrior 8 Deer Jaguar-Claw (1063-1115 A.D.), one of the most important governors of the Mixteca history.

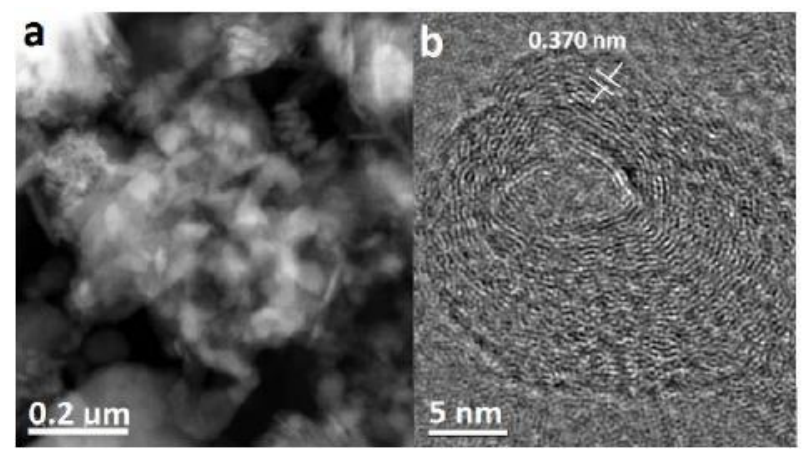

Figure 3. a) HAADF Image of black color observed in the Temple of the Niches at the site of Mayapan, by EDS analysis was identified $\mathrm{Fe}$ in $19 \%$ at. b) HRTEM image of the black color from the "Colombino Codex", carbonaceous structures were identified.

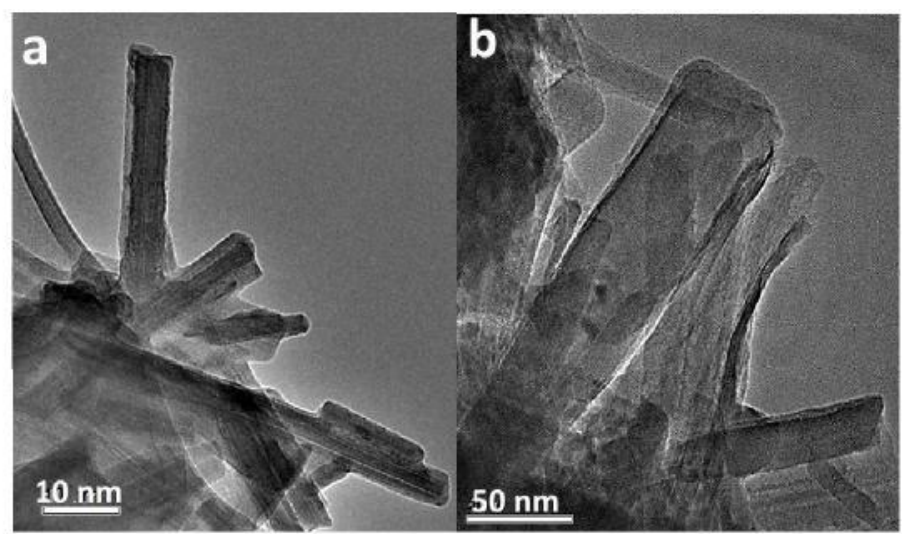

Figure 2. TEM images of blue color from Mayapan site (a) and blue color present in the "Colombino Codex". (b). In both cases palygorskite structures were identified with similar characteristics to "Maya blue".

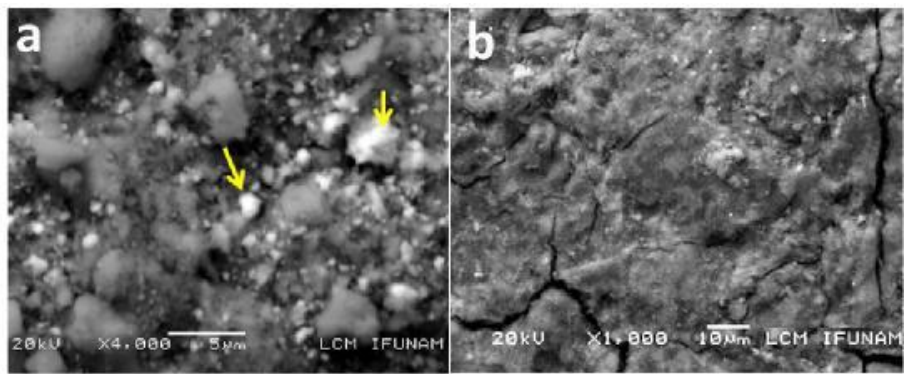

Figure 4. a) SEM image obtained with backscattered electrons (BSE) of the red color obtained from the murals of Mayapan. The agglomerates sample image with high contrast are rich in $\mathrm{Fe}$ (indicated with arrows), which are associated with the presence of $\mathrm{Fe}_{2} \mathrm{O}_{3}$. b) SEM image obtained with BSE from the red color in the Colombino codex, by EDS analysis not was identified $\mathrm{Fe}$ and high contrast areas were not observed. 